\title{
Effect of Structural Transformations on Precipitability and Polarity of Red Wine Phenolic Polymers
}

\author{
Ingrid Weilack, ${ }^{1}$ Christina Schmitz, ${ }^{1}$ James F. Harbertson, ${ }^{2,3}$ and Fabian Weber ${ }^{1 *}$
}

\begin{abstract}
Condensed tannins and polymeric pigments are essential red wine components that contribute to color stability, taste, and mouthfeel. Phenolic polymers in red wine consist of flavan-3-ol monomers and anthocyanins and cause the perception of astringency. Due to the chemical heterogeneity of proanthocyanidin polymers, analytical tools to determine the polymers' structural features are limited. Incorporation of anthocyanins increases the structural complexity even more and makes it almost impossible to assess the influence of structure on the perceived astringency. To better understand the structural diversity of red wine polymers, this study combines forced aging and FLASH-fractionation of polyphenolic wine extracts to reveal the relationship between phenolic polymers and two physicochemical properties: polarity and hydrophilicity. Red wine fractions were characterized using polarity, the octanol-water partitioning coefficient, protein precipitation assay, ultra high-performance liquid chromatography-mass spectrometry, and color. Tannin concentrations in wine decreased during forced aging and were constant in the corresponding extracts, suggesting alteration of the precipitation behavior. A simultaneous increase in precipitable polymeric pigments leads to the assumption that incorporating anthocyanins into tannin molecules alters their interactions with red wine polysaccharides and proteins, lowering tannin readings. Finding tannins and polymeric pigments in different FLASH-fractions indicates that precipitability of polymers is affected by their physicochemical properties, which in turn depend on the degree of polymerization as well as degree of pigmentation. The results of this study show that red wine astringency and its sub-qualities may be related to the increase in precipitable polymeric pigments during forced red wine aging and their putative enhanced interaction with wine polysaccharides, increasing understanding of astringency mechanisms.
\end{abstract}

Key words: interactions, physicochemical, pigmentation, polymers, red wine, tannins

Phenolic compounds are essential components of wine. Anthocyanins and flavan-3-ols are arguably of utmost importance for red wine quality since they contribute to color, stability, taste, and mouthfeel properties (Cheynier et al. 2006). While monomeric flavan-3-ols contribute to bitterness, tannins and oligomeric proanthocyanidins are largely responsible for the perception of astringency (Gawel 1998, Noble 1998). The composition of the tannins, expressed by the degree of polymerization and galloylation and the number of trihydroxyl-

\footnotetext{
${ }^{1}$ Institute of Nutritional and Food Sciences, Molecular Food Technology, University of Bonn, Friedrich-Hirzebruch-Allee 7, D 53115 Bonn, Germany; ${ }^{2}$ Washington State University, 2710 University Drive, Richland, WA 993547224; and ${ }^{3}$ Associate Professor of Enology, Washington State University, Viticulture and Enology Program, School of Food Science.

*Corresponding author (fabian.weber@uni-bonn.de; tel: +49-228-734462; fax: +49-228-734429)

Acknowledgments: This research project was financially supported by the German Ministry of Economics and Technology (via AiF) and the FEI (Forschungskreis der Ernährungsindustrie e.V., Bonn). Project AiF 20024 N.

Supplemental data is freely available with the online version of this article at www.ajevonline.org.

Manuscript submitted Oct 2020, revised Jan 2021, accepted Feb 2021

This is an open access article distributed under the CC BY license (https:// creativecommons.org/licenses/by/4.0/).

By downloading and/or receiving this article, you agree to the Disclaimer of Warranties and Liability. The full statement of the Disclaimers is available at http://www.ajevonline.org/content/proprietary-rights-notice-ajev-online. If you do not agree to the Disclaimers, do not download and/or accept this article. doi: 10.5344/ajev.2021.20064
}

ated monomers, are the driving forces for the intensity and quality of astringency perception, which is due to the loss of lubrication when polyphenols precipitate saliva proteins (Noble 1998, de Freitas and Mateus 2001, Vidal et al. 2003, Harbertson et al. 2014). Anthocyanins determine the color of young red wines and are extracted during winemaking. They have a key role in the modulation of color and mouthfeel properties during red wine aging.

Anthocyanins are transformed into more stable pigments, which is accompanied by a loss in wine color density (Bindon et al. 2014). Together with some low molecular weight wine constituents and yeast metabolites, anthocyanins can form pyranoanthocyanins (Fulcrand et al. 2006) or can be incorporated into tannin-like structures. Tannins that incorporate anthocyanins during red wine aging are called polymeric pigments (Remy et al. 2000).

An age-related decrease in tannin concentrations and mean degree of polymerization (mDP) was accompanied by a decline in perceived astringency (Chira et al. 2012). A conflicting study showed that tannin concentrations were not directly related to wine age and that tannin size increased during aging, indicating that lower astringency ratings of aged wines do not result solely from lower tannin concentrations and mDPs (McRae et al. 2012). Earlier studies (Vidal et al. 2004a, Weber et al. 2013) suggested that the formation of polymeric pigments found in aged red wine attenuates astringency. Hence, incorporation of anthocyanins may affect astringency perception even more than the concomitant increasing polymer length. 
Due to similar chemical structures and the chemical heterogeneity of proanthocyanidin polymer length, subunit composition, and constitution, analysis of these phenolics has proved difficult. Reversed-phase high-performance liquid chromatography-diode array detector-mass spectrometry (HPLC-DAD-MS) is commonly used to identify and quantify low molecular weight polyphenols, but this approach is limited for tannin analysis since tannins elute as a polydisperse hump (Ma et al. 2018). Methods used to partly characterize red wine polymers include tannin precipitation, either by proteins in combination with bisulfite bleaching (Harbertson et al. 2002, 2003) or by polysaccharides (Sarneckis et al. 2006). Acid-catalyzed cleavage of proanthocyanidins in the presence of nucleophilic agents like phloroglucinol (Kennedy and Jones 2001) is another approach to assess polymer composition. However, this method could not analyze pigmented tannins sufficiently (Vidal et al. 2004a), leaving the manifold structures of polymeric pigments still undefined. Consequently, the complex composition of, and alterations in, red wine polymers and their impact on astringency perception remain important topics for study.

This study used normal-phase FLASH-chromatography to fractionate red wine polyphenols by size and polarity. The fractions were chemically characterized, including the determination of their octanol-water partitioning coefficients $\left(\mathrm{K}_{\mathrm{OW}}\right)$ to measure hydrophilicity. $\mathrm{K}_{\mathrm{OW}}$ is influenced by tannin composition and red wine maturity (Merrell et al. 2018). Combining forced aging and fractionation of polyphenolic wine extracts clarified the relationships between polymeric pigments, tannins, and two physicochemical properties. Polarity and hydrophilicity were investigated to better understand the structural diversity of red wine polymers.

\section{Materials and Methods}

Materials. Acetic acid, hexane, hydrochloric acid $(\mathrm{HCl})$, potassium bisulfite, and acetonitrile were purchased from VWR International GmbH. Ethanol, bovine serum albumin fraction V, and (+)-catechin were purchased from Carl Roth. Silica gel $60 \AA$ (particle size 0.063 to $0.2 \mathrm{~mm}, 70-230 \mathrm{mesh}$ ) and sodium hydroxide were purchased from Honeywell Fluka. Urea, maleic acid, ferric chloride, triethanolamine (TEA), and octanol were purchased from Alfa Aesar. Sodium chloride and Amberlite XAD7 were purchased from Labochem Int. and Sigma-Aldrich, respectively.

Wine samples. Six bottles each of two different commercially available wines were analyzed: 2018 Cabernet Sauvignon from the Trapiche winery (Maipú, Mendoza, Argentina) and 2016 Cabernet Sauvignon from the Salentein winery (Tunuyán, Mendoza, Argentina). The wines were assessed in advance by Fourier-transform mid-infrared spectroscopy (FTIR) and in a bench tasting, which verified that both wines had no considerable differences in their general composition and sensory properties. Two different wines from two vintages were selected to investigate whether wine phenolic composition and tannin structures change differently during forced aging in an older wine than in a younger wine. The 2018 wine had 13\% ethanol by volume, $9 \mathrm{~g} / \mathrm{L}$ glycerol,
$\mathrm{pH} 3.7$, titratable acidity as $5.9 \mathrm{~g} / \mathrm{L}$ tartaric acid equivalents, $5 \mathrm{~g} / \mathrm{L}$ residual sugars, and $1935 \mathrm{mg} / \mathrm{L}$ catechin equivalents total phenolic content. The 2016 wine had $13.5 \%$ ethanol by volume, $10 \mathrm{~g} / \mathrm{L}$ glycerol, $\mathrm{pH} 3.8$, titratable acidity as $5.4 \mathrm{~g}$ tartaric acid equivalents/L, $5 \mathrm{~g} / \mathrm{L}$ residual sugars, and 2117 $\mathrm{mg} / \mathrm{L}$ catechin equivalents total phenolic content. Except for the phenolic content, these parameters were obtained using FTIR, with appropriate calibration (WineScan FT120 Basic, Foss). The total phenolic contents of the wines were not significantly different at $p \leq 0.05$. Free and total $\mathrm{SO}_{2}$ values were $6 \mathrm{mg} / \mathrm{L}$ and $70 \mathrm{mg} / \mathrm{L}$ for the 2016 wine and $10 \mathrm{mg} / \mathrm{L}$ and $100 \mathrm{mg} / \mathrm{L}$ for the 2018 wine, determined by titration. The samples were split into three pairs. Two were kept at $35^{\circ} \mathrm{C}$ for three or six weeks and were compared to the non-aged wines. All bottles were closed with screwcaps and the two bottles of each sample were pooled for all experiments.

Solid phase extraction and fractionation of phenolic compounds. To obtain a polyphenol rich extract from the wines, each wine sample was diluted with water $(1: 2)$ and loaded onto an Amberlite XAD7 column $(65 \mathrm{~mm} \times 450 \mathrm{~mm}$; $1.5 \mathrm{~L}$ bed volume), which was previously washed with $250 \mathrm{~mL}$ of a $0.1 \%(\mathrm{w} / \mathrm{v})$ sodium hydroxide solution and preconditioned with $2 \mathrm{~L}$ water. After elution of the wine, the column was washed with $2 \mathrm{~L}$ water $(1.3 \times$ the bed volume) to remove sugars and organic acids. The polyphenols were eluted with $\sim 3 \mathrm{~L}$ ethanol acidified with acetic acid $(29: 1 \mathrm{v} / \mathrm{v})$ at a gravity flow rate of $\sim 10 \mathrm{~mL} / \mathrm{min}$. The collected extracts were concentrated using a rotary evaporator and consecutively lyophilized. The fractionation was conducted on a self-packed silica gel $60 \AA$ column $(36 \mathrm{~mm} \times 460 \mathrm{~mm}$; $0.5 \mathrm{~L}$ bed volume) using a lowpressure chromatography pump (C-605 pump with C-615 pump manager, Büchi Labortechnik $\mathrm{GmbH}$ ). Isocratic elution involved three solvents: $60 \%$ hexane, $40 \%$ ethanol (solvent $\mathrm{A}$ ), ethanol with $1 \%$ formic acid (solvent $\mathrm{B}$ ), and $50 \%$ ethanol $(\mathrm{v} / \mathrm{v})$ with $1 \%$ formic acid (solvent $\mathrm{C}$ ). At a flow rate of $90 \mathrm{~mL} / \mathrm{min}$, the column was first rinsed with solvent $\mathrm{C}$ for $10 \mathrm{~min}$, then preconditioned with solvent A for another 10 min. Subsequently, $5 \mathrm{~mL}$ extract dissolved in solvent B was loaded onto the column at a concentration of $75 \mathrm{~g} / \mathrm{L}$. Solvents $\mathrm{A}, \mathrm{B}$, and $\mathrm{C}$ were successively applied to the column for 10 min each and changed manually. Elution was monitored at $280 \mathrm{~nm}$ and $520 \mathrm{~nm}$ with a Knauer BlueShadow 50D detector and the ClarityChrom Software (Knauer). According to the chromatogram obtained at $280 \mathrm{~nm}$, the fractions were manually combined. After complete elution, solvents were evaporated and the fractions were lyophilized. The column was washed with solvent $\mathrm{C}$ for $10 \mathrm{~min}$. Prior to further analyses, the lyophilized fractions and extracts were dissolved at concentrations of $2 \mathrm{~g} / \mathrm{L}$ in a wine-like solution (12\% ethanol by volume, $5 \mathrm{~g} / \mathrm{L}$ tartaric acid, $\mathrm{pH} 3.3$ adjusted with $\mathrm{NaOH}$ ).

Spectrophotometric analysis. Absorbance spectra of undiluted wines and sample solutions between 300 and $800 \mathrm{~nm}$ were determined using a Jasco V-730 double-beam spectrophotometer (JASCO Deutschland $\mathrm{GmbH}$ ) and a $1 \mathrm{~mm}$ path-length glass cuvette (Hellma GmbH \& Co. KG). After values were corrected to a $10 \mathrm{~mm}$ path length, cylindrical coordinates chroma $\left(\mathrm{C}^{*}\right)$ and hue $\left(\mathrm{h}^{\circ}\right)$ were calculated with 
the Spectra Manager Ver.2.14G (JASCO Deutschland GmbH) according to OIV recommendations (OIV 2006).

Chemical characterization. Anthocyanins were analyzed as described (Harbertson et al. 2009). Protein precipitation was combined with bisulfite bleaching to determine tannins and polymeric pigments (Harbertson et al. 2002, 2003) using a reformulated resuspension buffer (urea $8.3 \mathrm{M}, 5 \%$ TEA, pH 7 adjusted with $\mathrm{HCl}$ ) as described (Harbertson et al. 2015). To quantify total iron reactive phenolics, an aliquot of the sample was diluted with the previously mentioned resuspension buffer to a total volume of $875 \mu \mathrm{L}$ and incubated for $10 \mathrm{~min}$. Absorbance at $510 \mathrm{~nm}$ was measured before and after addition of $125 \mu \mathrm{L}$ ferric chloride solution. Tannins and total iron reactive phenolics were expressed as catechin equivalents (CE) according to an external calibration curve.

Octanol-water partitioning coefficient. One $\mathrm{mL}$ of the sample solution was thoroughly mixed with $1 \mathrm{~mL}$ octanol and vortexed for $10 \mathrm{sec}$. For faster separation of the phases, the samples were centrifuged at $9600 \mathrm{~g}$ for $10 \mathrm{~min}$. Subsequently, an aliquot of both phases was injected into the Shimadzu Nexera X2 ultra high-performance liquid chromatography (UHPLC)-DAD system (two Nexera X2 LC-30AD high-pressure gradient pumps, a Prominence DGU-20A5R degasser, a Nexera SIL-30AC autosampler $\left[15^{\circ} \mathrm{C}\right.$, injection volume $\left.2 \mu \mathrm{L}\right]$, a CTO-20AC Prominence column oven $\left[40^{\circ} \mathrm{C}\right]$, and an SPDM20A Prominence diode array detector; Shimadzu) using an Acquity HSS T3 column $(50 \mathrm{~mm} \times 2.1 \mathrm{~mm}, 1.8 \mu \mathrm{m}$; Waters $)$. At a flow rate of $0.5 \mathrm{~mL} / \mathrm{min}$, samples were eluted using the following gradient: $0 \mathrm{~min}, 50 \% \mathrm{~B} ; 2 \mathrm{~min}, 100 \% \mathrm{~B} ; 3.3 \mathrm{~min}$, $100 \% \mathrm{~B} ; 4 \mathrm{~min}, 50 \% \mathrm{~B} ; 7 \mathrm{~min}, 50 \% \mathrm{~B}$, with A being water/formic acid (97/3; v/v) and B being acetonitrile/formic acid (97/3; $\mathrm{v} / \mathrm{v}$ ). The partitioning coefficient was formed by the ratio of the samples' total peak area in the octanol phase and the water phase, respectively, according to the chromatogram at $280 \mathrm{~nm}$.

UHPLC-ESI-MS/MS. UHPLC-MS analysis of the fractions was performed on an Acquity UPLC I-Class system (Waters) consisting of a binary pump, an autosampler cooled at $10^{\circ} \mathrm{C}$, a column oven set at $40^{\circ} \mathrm{C}$, and a DAD scanning from 190 to $800 \mathrm{~nm}$. An Acquity HSS-T3 RP18 column $(150 \times 2.1 \mathrm{~mm} ; 1.8 \mu \mathrm{m}$ particle size $)$ combined with a precolumn (Acquity UPLC HSS T3 VanGuard, $100 \AA$, $2.1 \times 5 \mathrm{~mm}$, $1.8 \mu \mathrm{m}$ ), both from Waters, was used for separation. At a flow rate of $0.5 \mathrm{~mL} / \mathrm{min}$, analytes were eluted using the following gradient: $0 \mathrm{~min}, 5 \% \mathrm{~B} ; 8 \mathrm{~min}, 10 \% \mathrm{~B} ; 25 \mathrm{~min}, 25 \% \mathrm{~B}$; $26 \mathrm{~min}, 100 \% \mathrm{~B} ; 28 \mathrm{~min}, 100 \% \mathrm{~B} ; 29 \mathrm{~min}, 5 \% \mathrm{~B} ; 31 \mathrm{~min}$, $5 \% \mathrm{~B}$, with A being water/formic acid (97/3; v/v) and B being acetonitrile/formic acid (97/3; v/v). The injection volume was $5 \mu \mathrm{L}$. The UHPLC was coupled to an LTQ-XL ion trap mass spectrometer (Thermo Scientific, Inc.) equipped with an electrospray interface (ESI) operating in positive ion mode for analysis of anthocyanins and anthocyanin derivatives, and in negative ion mode for other polyphenols. For identification, mass spectra were recorded in the range of $\mathrm{m} / \mathrm{z} 120$ to 1500 with three consecutive mass scans $\left(\mathrm{MS}^{2}, 35 \%\right.$ normalized collision energy; $\mathrm{MS}^{3}, 45 \%$ normalized collision energy). The capillary was set at $325^{\circ} \mathrm{C}$ with a voltage of $40 \mathrm{~V}$ for $\mathrm{ESI}^{+}$ and at $350^{\circ} \mathrm{C}$ and a voltage of $-44 \mathrm{~V}$ for $\mathrm{ESI}^{-}$. The source voltage was maintained at 5 and $4 \mathrm{kV}$, respectively, at a current of $100 \mu \mathrm{A}$. The tube lens was adjusted to $70 \mathrm{~V}$ for ESI+ and $-105 \mathrm{~V}$ for ESI-. For quantification, specific $\mathrm{m} / \mathrm{z}$ values of 63 polyphenolic compounds were recorded in single ion monitoring measurements using one scan event.

Sensory analysis. To determine the effects of altered tannin structures on astringency during forced aging, overall astringency of the wines was evaluated by a panel tasting. The sensory panel was composed of 14 volunteer judges who participated in three training sessions prior to the final tasting. The first session was dedicated to differentiation between astringency, sourness, and bitterness by the panelists, who were familiarized with these tastes and sensations. Solutions of aluminum sulfate $(2 \mathrm{~g} / \mathrm{L})$, caffeine $(1.5 \mathrm{~g} / \mathrm{L})$, and tartaric acid $(2 \mathrm{~g} / \mathrm{L})$ in a 2018 Pinot noir base wine were presented to train astringency, bitterness, and sourness perception. The second session was dedicated to recognition of various aluminum sulfate concentrations $(0,0.5,1$, and $2 \mathrm{~g} / \mathrm{L})$. Panelists were advised to rank the standard solutions by ascending intensity. During the third session, the panelists were introduced to the intensity scale of the final tasting, which was a structured scale from 1 to 10 for "very low intensity" and "very high intensity," respectively. Two astringency standard solutions $(0.5 \mathrm{~g} / \mathrm{L}$ and $3 \mathrm{~g} / \mathrm{L})$ were presented and set as points 3 and 8 of the scale, after panel discussion. The final tasting was held in four individual sessions and three samples were evaluated in each of them. Wine samples were presented in a balanced random order in coded glasses and were tasted in duplicate. Reference astringency solutions were provided in each session. The panelists tasted $30 \mathrm{~mL}$ wine in individual booths while wearing a blindfold. They were advised to neutralize their oral cavity with water and bread and to wait $3 \mathrm{~min}$ before tasting the following sample.

Statistical analysis. Statistical analysis of the results was performed using XLSTAT (Version 2014.4.06, AddinSoft Technologies). For pairwise comparisons, an analysis of variance (ANOVA) with a selected significance level of $p<0.05$ was used.

\section{Results}

Wine samples and storage. The two wines chosen for this study had a similar initial composition and were stored at elevated temperature to accelerate reactions that occur normally during red wine aging. Two bottles of each wine were subjected to forced aging for three or six weeks. FTIR analysis revealed only negligible changes in the wines' general composition after storage. The color, assessed by the CIELab parameters $\mathrm{h}^{\circ}$ and $\mathrm{C}^{*}$ (Table 1), showed that the 2018 wines had greater color intensities than the 2016 wines. In contrast to the rather high $\Delta \mathrm{E}$ values between fresh and stored samples of 4.66 and 8.93 for the 2016 and 2018 wines, respectively, the color differences were hardly perceptible. The greater $\Delta \mathrm{E}$ value of the 2018 wines may be explained by a faster loss of anthocyanins in younger wines due to an exponential decline of anthocyanins during aging (McRae et al. 2012).

Since color intensity correlates with anthocyanin concentration and red wine maturity, the loss of color is consistent 
with the fast decline in anthocyanin concentrations during storage (Figure 1A). This development can be explained by the degradation, conversion, and incorporation of anthocyanins into pyranoanthocyanins and polymeric pigments. Figure $1 \mathrm{~B}$ and $1 \mathrm{C}$ indicate higher proportions of polymeric pigments in the 2016 wines than in the 2018 wines, whereby both contain more non-precipitable than precipitable polymeric pigments (PP). While the proportion of precipitable PP increased in both samples, the amount of non-precipitable PP increased in the 2018 wine only. In the 2016 wine, non-precipitable PP concentration leveled, whereas in the 2018 wine, the nonprecipitable PP concentration increased. While concentrations of precipitable PP increased, tannin concentrations decreased in the wine samples (Figure 1).

Since the wines did not show considerable differences in terms of sourness and bitterness, which was also proven by the FTIR data, only wine astringency was assessed further by sensory analysis. Sensory evaluation of perceived astringency revealed that the 2016 wine appears to induce higher but still moderate, astringency (Table 2). A four-way ANOVA of the astringency rating including vintage, storage, panelist, and replicate is presented (Supplemental Table 1). The astringency of the wines declined slightly with aging, consistent with the findings for tannin concentrations (Figure 1D). Interestingly, the astringency of the 2018 wine stored for three weeks dropped to 3.5, but increased during another three weeks of storage. This coincides only partially with the tannin concentrations, as tannin concentration declined constantly over time.

Isolation of a polyphenol-rich extract and fractionation using silica gel. The yields of polyphenol-rich extracts obtained by solid phase extraction using Amberlite XAD7

\begin{tabular}{|c|c|c|c|c|c|c|c|c|}
\hline \multirow{2}{*}{$\begin{array}{l}\text { Sample/ } \\
\text { weeks }\end{array}$} & \multicolumn{2}{|c|}{ Wine } & \multicolumn{2}{|c|}{ Fraction 1} & \multicolumn{2}{|c|}{ Fraction 2} & \multicolumn{2}{|c|}{ Fraction 3} \\
\hline & $\mathbf{h}^{\circ}$ & $C^{*}$ & $\mathbf{h}^{\circ}$ & $\mathrm{C}^{*}$ & $\mathbf{h}^{\circ}$ & $\mathbf{C}^{*}$ & $\mathbf{h}^{\circ}$ & $\mathrm{C}^{*}$ \\
\hline \multicolumn{9}{|l|}{2016} \\
\hline 0 & 14.97 & 29.12 & 69.82 & 15.21 & 36.23 & 53.21 & 40.39 & 45.44 \\
\hline 3 & 15.88 & 23.94 & 72.84 & 15.96 & 37.36 & 53.08 & 40.67 & 47.99 \\
\hline 6 & 16.13 & 24.62 & 72.84 & 13.80 & 37.81 & 52.22 & 42.75 & 46.86 \\
\hline \multicolumn{9}{|l|}{2018} \\
\hline 0 & 20.17 & 38.88 & 70.18 & 14.52 & 27.36 & 50.47 & 32.56 & 47.08 \\
\hline 3 & 17.60 & 30.10 & 71.16 & 13.09 & 28.44 & 51.15 & 35.19 & 41.75 \\
\hline 6 & 18.07 & 30.54 & 71.49 & 13.60 & 29.54 & 51.33 & 37.25 & 42.29 \\
\hline
\end{tabular}
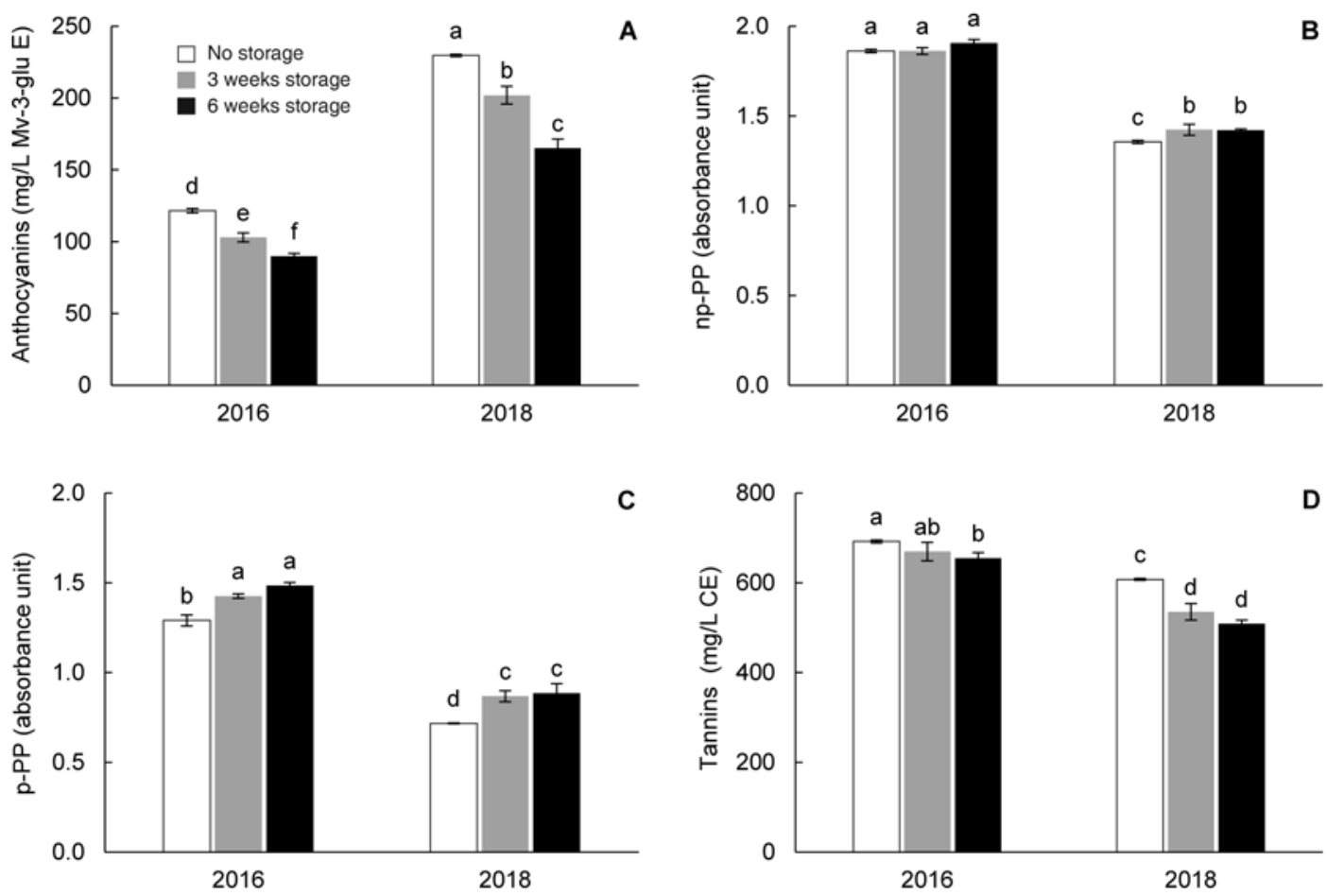

Figure 1 Phenolic composition, including total anthocyanins (A), non-precipitable polymeric pigments (np-PP; B), precipitable polymeric pigments (p-PP; C), and total tannins (D), of Cabernet Sauvignon wines after various lengths of storage at $35^{\circ} \mathrm{C}$. Results were obtained by photometric assays as described (Harbertson et al. 2002, 2003, 2009, 2015). Means are presented with standard deviation; $n=3$. Means having the same letters are not significantly different at $p \leq 0.05$. CE, catechin equivalents. 
as solid phase were $3.6 \pm 0.1 \mathrm{~g} / \mathrm{L}$ for the 2018 wines and $4.1 \pm 0.1 \mathrm{~g} / \mathrm{L}$ for the 2016 wines. For every wine sample, the low-pressure fractionation on silica gel was repeated six to eight times to produce enough material for analysis. The separation with silica gel works primarily on size exclusion, but hydrogen bonding between the phenolics and the silanol groups also plays an important role. The ternary isocratic separation of the injected extracts generated three fractions and the corresponding yields and distribution are shown (Table 3 ). The elution of the fractions was monitored at 280 and $520 \mathrm{~nm}$.

Composition of the FLASH fractions. Table 1 presents the color metrics recorded for the fractions of all wine samples. With chroma values of 13 to 16 and a color hue of $\sim 70$, fractions 1 had a light orange to yellow color, indicating a limited amount of red pigments. With color hues of 28 and 35 , respectively, fractions 2 and 3 of the 2018 wine appeared closer to a blueish red color than fractions 2 and 3 of the 2016 wine, which had values of 37 and 41 , respectively.

The protein precipitation assay showed that the highest number of anthocyanins were found in fraction 2 of the 2018 wine (Figure 2A). In all fractions, the amount of non-precipitable PP (Figure 2B) is greater than that of precipitable PP (Figure 2C) and tannins were only found in fractions 2 and 3. Tannins, polymeric pigments, and monomeric anthocyanins

Table 2 Astringency ratings of Cabernet Sauvignon wines at the various stages of storage at $35^{\circ} \mathrm{C}$ (means presented with standard deviation; $n=14$ ). Means within Astringency column having the same letters are not significantly different at $p \leq 0.05$. Tannin concentrations of the wines and the corresponding extracts; means presented with standard deviation; $n=3$. Concentrations with different capital letters are significantly different between the wines and the extracts $(p \leq 0.05)$.

\begin{tabular}{|c|c|c|c|}
\hline \multirow[b]{2}{*}{$\begin{array}{l}\text { Sample/ } \\
\text { weeks }\end{array}$} & \multicolumn{2}{|c|}{ Wine } & \multirow{2}{*}{$\begin{array}{c}\text { Extract } \\
\begin{array}{c}\text { Tannins } \\
\text { (mg/L CE) }\end{array}\end{array}$} \\
\hline & Astringency & $\begin{array}{c}\text { Tannins } \\
\text { (mg/L CE) }\end{array}$ & \\
\hline \multicolumn{4}{|l|}{2016} \\
\hline 0 & $6.52 \pm 1.50 \mathrm{a}$ & $692.05 \pm 3.24 \mathrm{~B}$ & $732.72 \pm 6.67 \mathrm{~A}$ \\
\hline 3 & $6.27 \pm 1.86 a b$ & $669.48 \pm 20.68 B C$ & $729.49 \pm 11.56 \mathrm{~A}$ \\
\hline 6 & $5.46 \pm 2.48 a b$ & $654.98 \pm 12.39 \mathrm{C}$ & $727.63 \pm 7.38$ A \\
\hline \multicolumn{4}{|l|}{2018} \\
\hline 0 & $5.50 \pm 2.13 a b$ & $607.66 \pm 4.15 \mathrm{D}$ & $587.15 \pm 2.12 \mathrm{D}$ \\
\hline 3 & $3.56 \pm 1.09 c$ & $535.39 \pm 18.45 E$ & $585.92 \pm 5.29 \mathrm{D}$ \\
\hline 6 & $4.53 \pm 1.47 b c$ & $508.49 \pm 8.64 \mathrm{E}$ & $605.81 \pm 2.61 \mathrm{D}$ \\
\hline
\end{tabular}

are absent in fraction 1, suggesting that fraction 1 is mainly composed of non-polar and non-phenolic substances.

Figure 3 presents the $\mathrm{K}_{\mathrm{OW}}$ of the fractions. $\mathrm{A} \mathrm{K}_{\mathrm{OW}}$ greater than 1 implies that the fraction is lipophilic, while values below 1 show the hydrophilicity of the contained compounds. The $\mathrm{K}_{\mathrm{OW}}$ of the fractions follows the elution gradient of the FLASH separation as expected, where fraction 1 had hydrophobic properties, while fractions 2 and 3 were both hydrophilic. The greatest hydrophilicity was found in fraction 3 of both vintages. Merrell et al. (2018) determined the $\mathrm{K}_{\mathrm{Ow}}$ of young and aged Cabernet Sauvignon wines and defined coefficients of $\sim 0.19$ for young wines. This is comparable to the values found here for the wine extracts (Figure 3A).

The results of the UHPLC-MS analyses showed that fraction 1 mainly contained gallic acid, monomeric flavan-3-ols, hydroxycinnamic acids, and oligomeric procyanidins, while malvidin-3-O-glucoside was the main compound in fractions 2 and 3 (Supplemental Tables 2 and 3). In agreement with the color and the precipitation assay, fraction 1 is characterized by the absence of anthocyanins and their derivatives.

Changes in the fractions during wine storage. Storage of the wines did not change the quantitative proportions of the fractions. Anthocyanins in fractions 2 and 3 declined in both vintages. The decrease in anthocyanins did not lead to a loss in color intensity (chroma), but is consistent with a change in hue that indicates structural changes of pigments rather than a mere loss. Non-precipitable PP (Figure 2B) in the 2018 wine increased in fraction 2 and decreased in fraction 3. Since a less polar solvent elutes fraction 2, these changes in the nonprecipitable PP fractions also indicate structural transformations of molecules, which correspond with declining polarities.

In the 2016 wine, non-precipitable PP concentrations remained constant in both fractions. In fractions 2 and 3, precipitable PP (Figure 2C) increased during storage. No changes in tannin concentrations were detected except in fraction 2 , which showed a slight decrease, indicating that the amount of less polar tannins decreased over time.

As a result of lower concentrations in polymeric pigments, the color of fraction 3 of the 2018 wine changed the most, while the color of the other fractions (Table 1) was rather constant. It is apparent that the hydrophilicity of the fractions changed significantly during storage, however alterations were small, with only fraction 3 of the 2018 wine undergoing considerable changes (Figure 3). Fraction 1 of the 2016

Table 3 Yields and proportions (in parentheses) of silica gel chromatography fractions of Cabernet Sauvignon XAD7 extracts after storage at $35^{\circ} \mathrm{C}$ (means presented with standard deviation; $\mathrm{n}=6$ to 8 ).

\begin{tabular}{|c|c|c|c|c|c|c|}
\hline & \multicolumn{6}{|c|}{ Yield (mg/g) (Proportion [\%]) } \\
\hline & \multicolumn{3}{|c|}{2016 sample } & \multicolumn{3}{|c|}{2018 sample } \\
\hline & 0 weeks & 3 weeks & 6 weeks & 0 weeks & 3 weeks & 6 weeks \\
\hline $\mathrm{F} 1$ & $\begin{array}{c}130.2 \pm 29.4 \\
(21.0 \pm 4.7)\end{array}$ & $\begin{array}{c}162.2 \pm 0.8 \\
(25.1 \pm 0.2)\end{array}$ & $\begin{aligned} 162.1 & \pm 3.7 \\
(24.9 & \pm 0.6)\end{aligned}$ & $\begin{array}{c}154.0 \pm 45.1 \\
(24.8 \pm 7.2)\end{array}$ & $\begin{array}{c}158.7 \pm 39.7 \\
(23.4 \pm 5.9)\end{array}$ & $\begin{array}{c}145.9 \pm 44.5 \\
(21.7 \pm 6.6)\end{array}$ \\
\hline $\mathrm{F} 2$ & $\begin{array}{c}396.8 \pm 6.8 \\
(64.0 \pm 1.2)\end{array}$ & $\begin{array}{c}368.4 \pm 31.6 \\
(57.0 \pm 4.5)\end{array}$ & $\begin{array}{c}378.7 \pm 12.4 \\
(58.1 \pm 1.9)\end{array}$ & $\begin{array}{r}421.2 \pm 29.1 \\
(67.7 \pm 4.7)\end{array}$ & $\begin{array}{c}450.4 \pm 2.3 \\
(66.4 \pm 0.3)\end{array}$ & $\begin{array}{r}451.1 \pm 71.2 \\
(67.1 \pm 10.6)\end{array}$ \\
\hline F3 & $\begin{array}{c}93.4 \pm 10.8 \\
(15.1 \pm 3.8)\end{array}$ & $\begin{array}{c}114.6 \pm 39.9 \\
(17.7 \pm 5.8)\end{array}$ & $\begin{array}{c}112.6 \pm 8.4 \\
(17.3 \pm 1.3)\end{array}$ & $\begin{array}{c}48.3 \pm 17.8 \\
(7.8 \pm 2.9)\end{array}$ & $\begin{array}{c}70.1 \pm 19.4 \\
(10.3 \pm 2.9)\end{array}$ & $\begin{array}{c}75.7 \pm 20.7 \\
(11.3 \pm 3.1)\end{array}$ \\
\hline
\end{tabular}


wine became more hydrophilic, while fraction 1 of the 2018 wine was more hydrophobic after storage. Hydrophilicity increased in fraction 2 of the 2016 wine and fraction 3 of the 2018 wine, while in fraction 3 of the 2016 wine and fraction
2 of the 2018 wine there was no change after six weeks' storage. Nevertheless, after three weeks storage, fraction 3 of the 2016 wine had greater water solubility and fraction 2 of the 2018 wine had less.
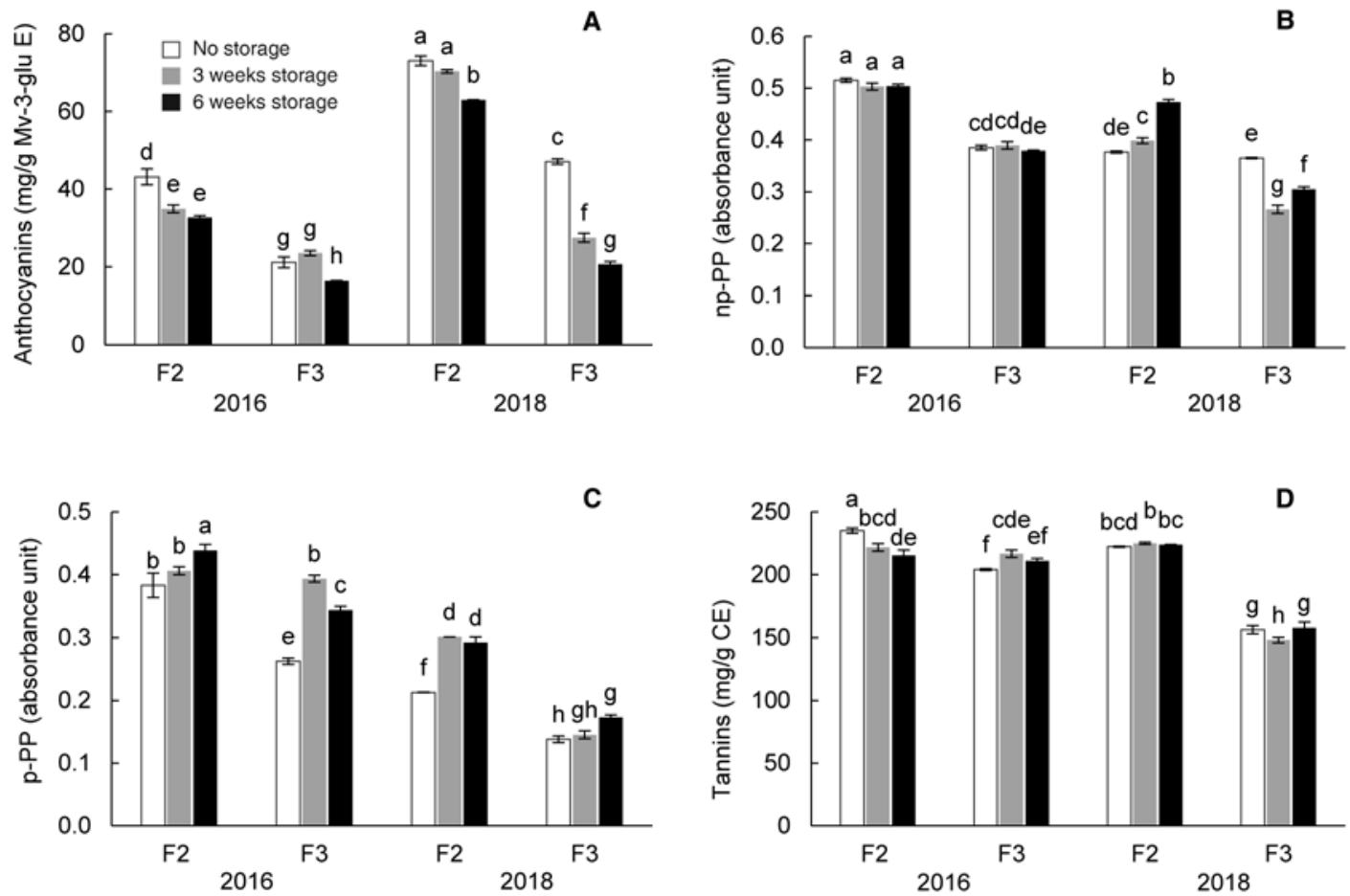

Figure 2 Phenolic composition, including total anthocyanins $(\mathbf{A})$, non-precipitable polymeric pigments (np-PP; $\mathbf{B})$, precipitable polymeric pigments $(\mathrm{p}-$ PP; C), and total tannins (D) of silica gel chromatography fraction 2 (F2) and fraction 3 (F3) of Cabernet Sauvignon XAD7 extracts after three lengths of storage at $35^{\circ} \mathrm{C}$. Results were obtained by photometric assays as described (Harbertson et al. 2002, 2003, 2009, 2015). Means are presented with standard deviation; $\mathrm{n}=3$. Means having the same letters are not significantly different at $p \leq 0.05$. $C E$, catechin equivalents.
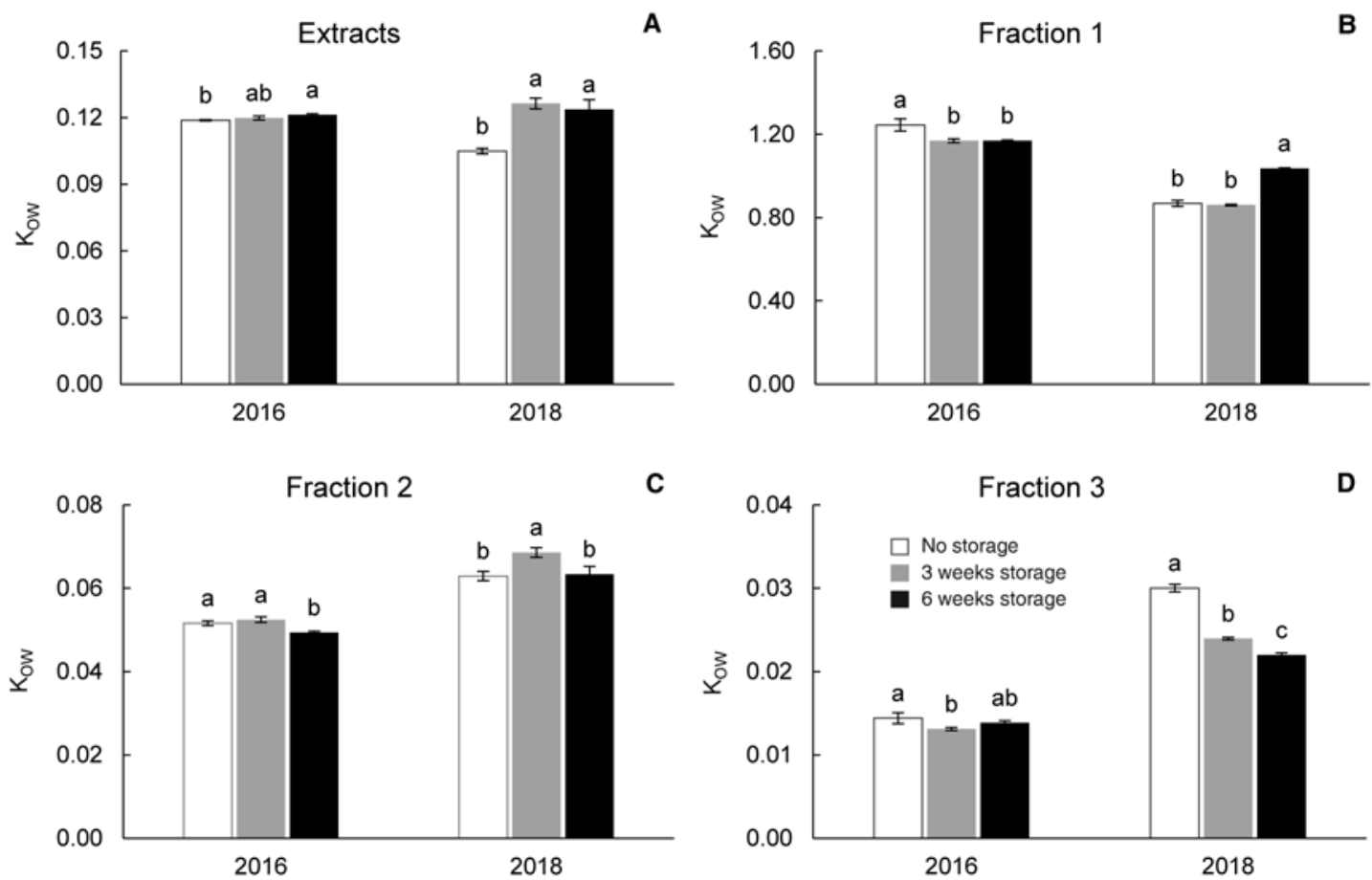

Figure 3 Octanol-water partitioning coefficients $\left(\mathrm{K}_{\mathrm{OW}}\right)$ of XAD7 extracts $(\mathbf{A})$ and of silica gel chromatography fractions 1 (B), 2 (C), and 3 (D) of Cabernet Sauvignon wines after three lengths of storage at $35^{\circ} \mathrm{C}$. Means are presented with standard deviation; $n=3$. Means within columns having the same letters are not significantly different at $p \leq 0.05$. 
In contrast to the anthocyanin concentrations, UHPLCMS showed no changes in the concentration of anthocyaninderived pigments like pyranoanthocyanins or anthocyaninflavanol oligomers (Supplemental Tables 2 and 3). Likewise, monomeric flavanols, benzoic acids, hydroxycinnamic acids, and flavanol dimers and trimers did not decrease.

\section{Discussion}

This study was conducted to gain a deeper understanding of structural transformations of polyphenols occurring during forced red wine aging and their effects on astringency perception. Earlier studies associated red wine astringency with tannin concentration and wine vintage (Boselli et al. 2004, Landon et al. 2008, Chira et al. 2011). Accordingly, 2018 wine was expected to be more astringent than the 2016 wine and both wines were expected to decrease in astringency during forced aging; neither of which was actually observed (Table 2). This indicates that astringency is not only influenced by tannin concentrations but also by structural and compositional differences (Gawel 1998) like the degree of polymerization (Chira et al. 2012) and the composition of tannin subunits; in particular, their degree of galloylation and trihydroxylation on the B-ring (Vidal et al. 2003). Roughness of astringency increases with proceeding galloylation and decreases with the number of epigallocatechin subunits (Vidal et al. 2003). To compare tannin concentrations in the wines and extracts, the values obtained for the extracts were referenced to the corresponding volumes of the wines considering the respective yield (Table 3 ). In contrast to the results obtained for the wines, significantly greater tannin concentrations and no significant changes in tannin concentrations were found in the XAD7 extracts of the corresponding wines. These differences may be explained by interactions of the tannins with wine polysaccharides that are eliminated by the extraction procedure. The polysaccharides can form complexes with the tannins, leading to an impaired precipitability with the bovine serum albumin (BSA) (Mateus et al. 2004) used to quantify tannins, which results in lower tannin readings. Since the differences in tannin concentrations between wines and extracts increased, these interactions may become more pronounced when the wine is subjected to forced aging, probably due to structural changes in the tannins. Precipitable PPs can be regarded as pigmented tannins, since they are part of the tannin fraction determined after precipitation with BSA. The results show increasing precipitable PP ratios combined with decreasing or constant tannin levels, indicating a progressive incorporation of anthocyanins into tannin molecules. An investigation of haze formation in red wines treated with carboxymethyl cellulose (CMC) found that CMC forms haze with wine proteins rather than with tannins, and proposed a protein-bridged reaction between anthocyanins and CMC that leads to their precipitation (Sommer et al. 2016). Accordingly, incorporation of anthocyanins into tannin molecules changes the interaction of tannin subunits with polysaccharides and proteins, camouflaging them from analysis. Polysaccharides may also interact directly with BSA (de Freitas et al. 2003), which is used for tannin precipitation and might be another reason for the underestimation of tannins in wine samples. Astringency perception is also affected by wine polysaccharides that interact with red wine tannins and salivary proteins (Vidal et al. 2004b, Watrelot et al. 2017). Panelists were only requested to rate overall astringency intensity, which was compared to the drying mouthfeel evoked by aluminum sulfate. Future research should look at the perception of different astringency sub-qualities to investigate whether decreased astringency rather represents a change in sub-qualities toward a less harsh mouthfeel. These results show that the tannin concentration may not be the only factor that should be considered to evaluate astringency and the sensory quality of the wine in general. Gel permeation chromatography fractions with the most polymeric pigments and rather small tannin concentrations elicited the lowest astringency and green and dry tannins intensity (Weber et al. 2013). A continuously increasing precipitable $\mathrm{PP} /$ tannin ratio in the wines may have favored perception of a softer astringency.

The mechanism of astringency perception is based on tannin-protein interactions leading to insoluble precipitates, increasing friction, and reduced lubrication in the oral cavity (Baxter et al. 1997). A proposed model for protein precipitation is driven initially by hydrophobic interactions between the proline residues of proline-rich proteins and the aromatic flavonoid rings (Charlton et al. 2002). These soluble aggregates are further stabilized through hydrogen bonding, leading to cross-linked tannin-protein complexes and their precipitation, suggesting that hydrophilicity is an important factor determining the astringency of distinct compounds.

The ratio of the concentration of lipophilic to hydrophilic compounds in the fractions is reflected by the $\mathrm{K}_{\mathrm{OW}}$. The generally greater anthocyanin concentrations in fraction 2 of all samples raised the expectation of greater hydrophilicities of this fraction compared with fraction 3. Since this was not the case, other compounds, like polymeric pigments and tannins, must contribute more to the overall hydrophilicity of the fractions. Tannins with higher degrees of polymerization had lower $\mathrm{K}_{\mathrm{OW}}$ than their corresponding flavan-3-ol subunits (Hagerman et al. 1998). Hence, a greater degree of polymerization results in greater hydrophilic properties and precipitability. The hydrophobic character of fraction 1 is the result of the presence of monomeric flavan-3-ols, oligomeric procyanidins, and benzoic and hydroxycinnamic acids.

The leveling concentrations of non-precipitable PP in fractions 2 and 3 of the 2016 wine lead to the assumption that the wines reached a maximum non-precipitable PP, as previously reported (Merrell et al. 2018), and which may have two explanations. Either the formation and degradation processes of non-precipitable PP reached an equilibrium or formation of polymeric pigments in the older red wine that was subjected to forced aging favored development of high-molecular weight pigments that are not included in the non-precipitable PP measurement. Precipitation with BSA increased with tannin polymer size, indicating that polymeric pigments that are resistant against $\mathrm{SO}_{2}$ bleaching and not precipitated with BSA include oligomeric anthocyanin adducts in addition to pyranoanthocyanins (Harbertson et al. 2014). The UHPLC-MS 
results showed no considerable changes in the concentration of pyranoanthocyanins and anthocyanin-flavanol dimers (Supplemental Tables 2 and 3). Hence, the protein precipitation assay indicates that anthocyanins are incorporated into existing polymeric structures to form polymeric pigments, rather than forming new oligomeric pigments that grow in size. This is supported by earlier studies that demonstrated that direct adducts of tannins and anthocyanins are formed after the preceding acid-catalyzed cleavage of procyanidins (Haslam 1980, Salas et al. 2003, 2004). The products formed during this reaction may still be regarded as polymeric structures, although they may be of lower molecular weight due to the breakdown process.

The decline of tannins in fraction 2 of the 2016 wine, together with a rise of precipitable PP, results in increased hydrophilicity. This indicates that tannins initially found in fraction 2 of the 2016 wine are rather small and, therefore, non-polar and hydrophobic, while the proceeding incorporation of anthocyanins during forced aging leads to more water-soluble polymeric pigments (Singleton and Trousdale 1992, Merrell et al. 2018). Since the tannin concentration of fraction 3 of the 2016 wine remains constant, the corresponding partitioning coefficients follow the development of precipitable PP, showing that fraction 3 of the 2016 wine contains large and polar tannins that were progressively pigmented during storage. In the 2018 wines, tannin concentrations in fractions 2 and 3 showed no changes over time and accordingly, hydrophilicity seems to be affected by the compositional changes in precipitable PP and non-precipitable PP. As the determination of polymeric pigments is based on their absorption at $520 \mathrm{~nm}$, the protein-precipitation assay does not distinguish among polymers with different intramolecular compositions (Weber et al. 2013). Hence, no conclusion can be drawn about the exact size of the molecules and the proportion of anthocyanins incorporated. The chemical composition of red wine polymers obtained by gel permeation chromatography, based on separation of molecules by size and polarity, has been examined by Weber et al. (2013). Combining several analytical techniques, they showed that earlyeluting fractions were composed of large and less pigmented polymers. Further retention on the column eluted polymers of decreasing molecular size and increasing anthocyanin incorporation, followed by less-pigmented, proanthocyanidinlike oligomers. Together with the results of the present study, the changes in hydrophilicity and distribution of polymeric pigments between fractions visualize the compositional transformations of red wine polymers. The hydrophilicity of fraction 2 of the 2018 wine decreased during the first three weeks, while the precipitable PP increased. Because fraction 2 contains less-polar, smaller polymers than fraction 3 , this suggests an increase in the amount of smaller precipitable PP, rather than an increase in the proportion of incorporated anthocyanins, i.e., the degree of pigmentation.

In contrast, the increased hydrophilicity after six weeks resulted from increased non-precipitable PP or rather, the augmented pigmentation of non-precipitable PP. The progressive increase in hydrophilicity of fraction 3 from the 2018 wine is caused by ongoing new formation of larger precipitable PP or by continuous pigmentation of already existing, large precipitable PP, with simultaneous decrease of smaller, nonprecipitable PP that are less pigmented.

The different sub-qualities of astringency perception are explained by the varying manifestation of the physico-chemical interactions between tannins and proteins, which are specific and depend on the molecular weight, 3D structure, and water-solubility of tannins; that is, according to Haslam (1996), one of the main factors for tannin complexation (Simon et al. 2003). Being of a certain size, polyphenols can act as multidentate ligands, binding more than one site of the protein (de Freitas and Mateus 2001), leading to formation of protein-tannin networks and eventual precipitation (Cala et al. 2010). The formation of such networks and resulting astringent sensations were influenced by stereochemistry and conformation of procyanidins, because intramolecular stacking hinders the development of protein-tannin aggregates (Cala et al. 2010, Quijada-Morín et al. 2012). An earlier study showed that the interactions between red wine tannins and a prolinerich peptide changed with wine age, toward less-pronounced hydrophobic interactions (McRae et al. 2010). The authors attribute this to a change in tannin structures, like the incorporation of anthocyanins.

Tannins obtained by liquid-liquid extraction with butanol were smaller in size, more hydrophobic, and comprise more red pigments than the aqueous fractions, which was inversely correlated with perceived astringency (McRae et al. 2013). Our study and others argue for the concept of pigmented tannins being less astringent than non-pigmented tannins (McRae et al. 2013, Weber et al. 2013). Accordingly, a greater degree of pigmentation does not necessarily result in lower hydrophobicity, since other structural features also contribute to overall hydrophobicity of tannins. The greater hydrophobicity of the butanol tannins may be due to greater oxidation and an increased amount of intramolecular bonds, possibly leading to fewer binding sites and reduced astringency (McRae et al. 2013). The interim decline in astringency of the 2018 wine stored for three weeks may be the consequence of the considerably higher non-precipitable PP in fraction 2 and the increased hydrophobicity of this fraction at this point in forced aging, while further alterations of the tannins lead to increased astringency after six weeks of storage.

Finding tannins and PP in both fractions 2 and 3 indicates that size is not solely determinant of protein precipitation by these polymers, it is also affected by physicochemical properties, which in turn depend on tannin molecule size and the ratio of incorporated anthocyanins, among other factors. However, it has still to be investigated how the elongation of polymers by anthocyanins as well as flavanols influences the protein precipitability.

\section{Conclusion}

The present results reveal that a wide structural variety of pigments can be found within the classification of polymeric pigments into two categories. This variety is based on differences in subunits, chain length, and ratio of incorporated 
anthocyanins, and leads to polymers with different physicochemical properties that can be visualized by the $\mathrm{K}_{\mathrm{OW}}$ and FLASH fractionation. The change in polarity of polymeric pigments in turn alters their ability to interact with wine polysaccharides and saliva proteins. Since the presumed proceeding incorporation of anthocyanins into tannin molecules, which can be assumed by the presented increase in precipitable PP, appears to reduce the measurability of precipitable tannins during forced aging, a special role may be assigned to the interactions of precipitable PP with polysaccharides and proteins. The formation of precipitable PPs during forced red wine aging and their putative enhanced interactions with wine polysaccharides obviously play a key role in the perception of red wine astringency. In particular, the perception of different sub-qualities of astringency seems to be related to the proportion of precipitable PP and polysaccharides, which should be clarified during further research.

\section{Literature Cited}

Baxter NJ, Lilley TH, Haslam E and Williamson MP. 1997. Multiple interactions between polyphenols and a salivary proline-rich protein repeat result in complexation and precipitation. Biochem 36:5566-5577.

Bindon KA, McCarthy MG and Smith PA. 2014. Development of wine colour and non-bleachable pigments during the fermentation and ageing of (Vitis vinifera L. cv.) Cabernet Sauvignon wines differing in anthocyanin and tannin concentration. LWT-Food Sci Technol 59:923-932.

Boselli E, Boulton RB, Thorngate JH and Frega NG. 2004. Chemical and sensory characterization of DOC red wines from Marche (Italy) related to vintage and grape cultivars. J Agric Food Chem 52:3843-3854.

Cala O, Pinaud N, Simon C, Fouquet E, Laguerre M, Dufourc EJ and Pianet I. 2010. NMR and molecular modeling of wine tannins binding to saliva proteins: Revisiting astringency from molecular and colloidal prospects. FASEB J 24:4281-4290.

Charlton AJ, Baxter NJ, Khan ML, Moir AJG, Haslam E, Davies AP and Williamson MP. 2002. Polyphenol/peptide binding and precipitation. J Agric Food Chem 50:1593-1601.

Cheynier V, Dueñas-Paton M, Salas E, Maury C, Souquet JM, SarniManchado P and Fulcrand H. 2006. Structure and properties of wine pigments and tannins. Am J Enol Vitic 57:298-305.

Chira K, Pacella N, Jourdes M and Teissedre PL. 2011. Chemical and sensory evaluation of Bordeaux wines (Cabernet Sauvignon and Merlot) and correlation with wine age. Food Chem 126:1971-1977.

Chira K, Jourdes M and Teissedre PL. 2012. Cabernet Sauvignon red wine astringency quality control by tannin characterization and polymerization during storage. Eur Food Res Technol 234:253-261.

de Freitas V and Mateus N. 2001. Structural features of procyanidin interactions with salivary proteins. J Agric Food Chem 49:940-945.

de Freitas V, Carvalho E and Mateus N. 2003. Study of carbohydrate influence on protein-tannin aggregation by nephelometry. Food Chem 81:503-509.

Fulcrand H, Dueñas M, Salas E and Cheynier V. 2006. Phenolic reactions during winemaking and aging. Am J Enol Vitic 57:289-297.

Gawel R. 1998. Red wine astringency: A review. Aust J Grape Wine Res 4:74-95.

Hagerman AE, Rice ME and Ritchard NT. 1998. Mechanisms of protein precipitation for two tannins, pentagalloyl glucose and epicatechin ${ }_{16}$ $(4 \rightarrow 8)$ catechin (procyanidin). J Agric Food Chem 46:2590-2595.
Harbertson JF, Kennedy JA and Adams DO. 2002. Tannin in skins and seeds of Cabernet Sauvignon, Syrah, and Pinot noir berries during ripening. Am J Enol Vitic 53:54-59.

Harbertson JF, Picciotto EA and Adams DO. 2003. Measurement of polymeric pigments in grape berry extracts and wines using a protein precipitation assay combined with bisulfite bleaching. Am J Enol Vitic 54:301-306.

Harbertson JF, Mireles MS, Harwood ED, Weller KM and Ross CF. 2009. Chemical and sensory effects of saignée, water addition, and extended maceration on high Brix must. Am J Enol Vitic 60:450-460.

Harbertson JF, Kilmister RL, Kelm MA and Downey MO. 2014. Impact of condensed tannin size as individual and mixed polymers on bovine serum albumin precipitation. Food Chem 160:16-21.

Harbertson JF, Mireles M and Yu Y. 2015. Improvement of BSA tannin precipitation assay by reformulation of resuspension buffer. Am J Enol Vitic 66:95-99.

Haslam E. 1980. In vino veritas: Oligomeric procyanidins and the ageing of red wines. Phytochemistry 19:2577-2582.

Haslam E. 1996. Natural polyphenols (vegetable tannins) as drugs: Possible modes of action. J Nat Prod 59:205-215.

Kennedy JA and Jones GP. 2001. Analysis of proanthocyanidin cleavage products following acid-catalysis in the presence of excess phloroglucinol. J Agric Food Chem 49:1740-1746.

Landon JL, Weller K, Harbertson JF and Ross CF. 2008. Chemical and sensory evaluation of astringency in Washington State red wines. Am J Enol Vitic 59:153-158.

Ma W, Waffo-Téguo P, Alessandra Paissoni M, Jourdes M and Teissedre PL. 2018. New insight into the unresolved HPLC broad peak of Cabernet Sauvignon grape seed polymeric tannins by combining CPC and Q-ToF approaches. Food Chem 249:168-175.

Mateus N, Carvalho E, Luís C and de Freitas V. 2004. Influence of the tannin structure on the disruption effect of carbohydrates on protein-tannin aggregates. Anal Chim Acta 513:135-140.

McRae JM, Falconer RJ and Kennedy JA. 2010. Thermodynamics of grape and wine tannin interaction with polyproline: Implications for red wine astringency. J Agric Food Chem 58:12510-12518.

McRae JM, Dambergs RG, Kassara S, Parker M, Jeffery DW, Herderich MJ and Smith PA. 2012. Phenolic compositions of 50 and 30 year sequences of Australian red wines: The impact of wine age. J Agric Food Chem 60:10093-10102.

McRae JM, Schulkin A, Kassara S, Holt HE and Smith PA. 2013. Sensory properties of wine tannin fractions: implications for in-mouth sensory properties. J Agric Food Chem 61:719-727.

Merrell CP, Larsen RC and Harbertson JF. 2018. Effects of berry maturity and wine alcohol on phenolic content during winemaking and aging. Am J Enol Vitic 69:1-11.

Noble AC. 1998. Why do wines taste bitter and feel astringent? In Chemistry of Wine Flavor. Waterhouse AL and Ebeler SE (eds.), pp. 156-165. American Chemical Society, Washington, DC.

OIV. 2006. Determination of chromatic characteristics according to CIELab. Resolution Oeno 1/2006. OIV, Paris, France.

Quijada-Morín N, Regueiro J, Simal-Gándara J, Tomás E, RivasGonzalo JC and Escribano-Bailón MT. 2012. Relationship between the sensory-determined astringency and the flavanolic composition of red wines. J Agric Food Chem 60:12355-12361.

Remy S, Fulcrand H, Labarbe B, Cheynier V and Moutounet M. 2000. First confirmation in red wine of products resulting from direct anthocyanin-tannin reactions. J Sci Food Agric 80:745-751.

Salas E, Fulcrand H, Meudec E and Cheynier V. 2003. Reactions of anthocyanins and tannins in model solutions. J Agric Food Chem 51:7951-7961. 
Salas E, Atanasova V, Poncet-Legrand C, Meudec E, Mazauric JP and Cheynier V. 2004. Demonstration of the occurrence of flavanol-anthocyanin adducts in wine and in model solutions. Anal Chim Acta 513:325-332.

Sarneckis CJ, Dambergs RG, Jones P, Mercurio M, Herderich MJ and Smith PA. 2006. Quantification of condensed tannins by precipitation with methyl cellulose: Development and validation of an optimised tool for grape and wine analysis. Aust J Grape Wine Res 12:39-49.

Simon C, Barathieu K, Laguerre M, Schmitter JM, Fouquet E, Pianet I and Dufourc EJ. 2003. Three-dimensional structure and dynamics of wine tannin-saliva protein complexes. A multitechnique approach. Biochemistry 42:10385-10395.

Singleton VL and Trousdale EK. 1992. Anthocyanin-tannin interactions explaining differences in polymeric phenols between white and red wines. Am J Enol Vitic 43:63-70.

Sommer S, Dickescheid C, Harbertson JF, Fischer U and Cohen SD. 2016. Rationale for haze formation after carboxymethyl cellulose (CMC) addition to red wine. J Agric Food Chem 64:6879-6887.
Vidal S, Francis IL, Guyot S, Marnet N, Kwiatkowski M, Gawel R, Cheynier V and Waters EJ. 2003. The mouth-feel properties of grape and apple proanthocyanidins in a wine-like medium. J Sci Food Agric 83:564-573.

Vidal S, Francis L, Noble A, Kwiatkowski M, Cheynier V and Waters E. 2004a. Taste and mouth-feel properties of different types of tannin-like polyphenolic compounds and anthocyanins in wine. Anal Chim Acta 513:57-65.

Vidal S, Francis L, Williams P, Kwiatkowski M, Gawel R, Cheynier V and Waters E. 2004b. The mouth-feel properties of polysaccharides and anthocyanins in a wine like medium. Food Chem 85:519-525.

Watrelot AA, Schulz DL and Kennedy JA. 2017. Wine polysaccharides influence tannin-protein interactions. Food Hydrocolloid 63:571-579.

Weber F, Greve K, Durner D, Fischer U and Winterhalter P. 2013. Sensory and chemical characterization of phenolic polymers from red wine obtained by gel permeation chromatography. Am J Enol Vitic 64:15-25. 